\title{
Influence of Monensin, Yeast, Selenoproteinand S odium Selenite Supplement on change of Offspring Sex Ratio at Birthof Sheep
}

\author{
Saman Saedi ${ }^{1}$, Hossein Daghigh Kia ${ }^{2 *}$, Leila Ahmadzadeh ${ }^{2}$ and Ali Hosseinkhani ${ }^{2}$ \\ ${ }^{1}$ Department of Animal Science, Shiraz University, Iran \\ ${ }^{2}$ Department of Animal Science, University of Tabriz, Iran
}

Submission: October 01, 2018; Published: November 01, 2018

"Corresponding author: Hossein Daghigh Kia, Department of Animal Science,University of Tabriz, Postal Code: 5166614766, Iran.

\begin{abstract}
The female reproductive organ and layers around the oocyst are affected by some ration ions that are able to facilitate the penetration of sperm with specific chromosome type (X or Y) and change the sex ratio in mammal offsprings. To check this, 66 Ghezel ewes,2-3 years-old and with average weight of $55 \pm 2$ were chosen and all ewes were allotted randomly into six experimental groups ( $\mathrm{n}=11)$ as follows: A; Control (only used Basal diet), B; Flushing diet, C; Flushing diet plus vitamin E plus Seleno protein, D; Flushing diet plus vitamin E plus Sodium Selenite, E; Flushing diet plus Monensin sodium, F; Flushing diet plus Saccharomyces cerevisiae yeast. The levels of serum minerals including calcium, magnesium, sodium and potassium concentrations were measured. Results showed that ewes in groups $\mathrm{E}$ and $\mathrm{F}$ had more serum calcium and magnesium compared with other groups $(\mathrm{P}<0.01)$ and the number of female lambs was the highest in these two groups. Ewes in group $F$ had the lowest serum potassium and sodium and ratio of male to female lamb births (0.25) compared to other groups. This study indicated that ewes fed with Monensin and yeast (high Ca \& Mg) rich ratios tended to have female progeny, also, the ewes fed with selenoprotein and sodium Selenit (high Na \& K) rich ratios tended to have male progeny.
\end{abstract}

Keywords: Sex ratio;Selenoprotein; Sodium selenite; Ghezel ewes; Monensin; Saccharomyces Cerevisiae yeast.

\section{Introduction}

The male-to-female sex ratio at the time of conception (primary sex ratio) and the secondary sex ratio at birth can be strikingly skewed from the theoretical 1:1 expected ratio [1,2]. Mammals usually produce approximately equal numbers of sons and daughters, but there are exceptions to this general rule, as has been observed in ruminant ungulate species, where the sexallocation hypothesis of Trivers and Willard has provided a rational evolutionary underpinning to adaptive changes in sex ratio [3]. It has been revealed that many factors including, nutritional factors (food restriction of female, diet with low- and high-energy intake, absorption of minerals) and non-nutritional factors (timing of insemination, timing of mating, body condition score and stress) are effective on offspring sex and change in offspring sex ratio in mammalians [3].

Among reproductive physiologists it is widely thought that the sex of the offspring in mammals is a matter of chance, depending on whether an X- or a Y-chromosome bearing spermatozoon from the male arrives at the ovum first [4].The latest medical technique that can be used to select for sex is sperm sorting. New technologies allow sperm to be sorted into those carrying $\mathrm{X}$ or $\mathrm{Y}$ chromosomes with varying degrees of accuracy. To date, the most successful way in which to sort sperm is flow cytometry, which has been branded as the Micro Sort Technique (Steinbock). Sex selection using flow cytometry results from distinguishing between the identifiable differences between the $\mathrm{X}$ and $\mathrm{Y}$ chromosomes as the $\mathrm{X}$ chromosome is larger than the $\mathrm{Y}$ chromosome. The sorted sperm is then used to artificially inseminate the female. This is the least expensive method (at about $\$ 2,300$ US per cycle13) of selecting for sex [4]. Hence, this method is not suitable for farm animal $\neg$ s and a more cost-efficient method should be used.

There are also methods which use different food combinations and special diets to maximize the chance of having a fetus with specific sex. Some believe that the ratio of the mineral's sodium, potassium, calcium and magnesium are important in determination of fetus gender [5,6].It is reported that both $\mathrm{Mg}$ absorption and retention increased when steers were fed Monensin [7]. Also, high levels of sodium in the sodium selenite may increase the level of blood sodium, potassium and several metabolites and elements in the blood [8].

Therefore, the aim of this study was to determine the influence of Monensin, SaccharomycesCerevisiaeYeast, Selenoprotein with Vitamin E and sodium selenite with Vitamin E supplement on 
change in offspring sex ratio in Ghezelewe in the Flushing period and considerhow the nutrition of the mother can affect the sex ratio of her progeny.

\section{Materials and methods}

\section{Animals, diets, and experimental procedure}

This study was undertaken in Khalatpooshan Research Center of Tabriz University. In this study 66 Ghezelewes aged 2-3yearsold and average weight of $55 \pm 2$ were chosen and then closely inspected to ensure their health and reproduction performance integrity. All ewes were allotted randomly into six experimental groups $(\mathrm{n}=11)$ as follows:

a) Control (only used Basal diet);

b) Flushing diet; c) Flushing diet plus vitamin E plus organic selenium;

d) Flushing diet plus vitamin E plus sodium selenite;

e) Flushing diet plus Monensin sodium;

f) Flushing diet plus Saccharomyces cerevisiaeyeast.

All ewes received flushing diet during 5weeks (two weeks before and three weeks after mating). All diets were formulated according to NRC 1985 [9] recommendations and were given to ewes as total mix ration (TMR) (Table 1). In order to conduct this study, the estrus synchronization of ewes was first accomplished using CIDR (EAZI BREED; Pfizer NEW Zealand LTD, Auckland, NEW Zealand) for 14days; then the ewes PMSG received 400 units of hormone [Bioniche Animal Health (LA Asia) Pty Ltp/Australia (preg-necol injection)]. Ewes were naturally mated using Ghezel rams that were introduced $24 \mathrm{~h}$ after the administration of PSMG.

Table 1: Composition of experimental treatments.

\begin{tabular}{|c|c|c|c|c|c|c|}
\hline Food ingredients & Treatment A & Treatment B & Treatment C & Treatment D & Treatment E & Treatment F \\
\hline Wheat Bran & - & 11 & 11 & 11 & 11 & 11 \\
\hline Soybean Meal & - & 8 & 8 & 8 & 8 & 8 \\
\hline Protein Premix & - & 1.5 & 1.5 & 1.5 & 1.5 & 1.5 \\
\hline Barley Grain & - & 73 & 73 & 73 & 73 & 73 \\
\hline $\mathrm{NaCl}$ & - & 0.5 & 0.5 & 0.5 & 0.5 & 0.5 \\
\hline Molasses & - & 6 & 6 & 6 & 6 & 6 \\
\hline \multicolumn{7}{|l|}{ Experimental additives } \\
\hline Sodium Selenit (gr/ewe/d) & - & - & - & 0.0135 & - & - \\
\hline Selenoprotein (gr/ewe/d) & - & - & 0.135 & - & - & - \\
\hline Vit E (gr/ewe/d) & - & - & 0.048 & 0.048 & - & - \\
\hline Monensin (mg/ewe/d) & - & - & - & - & 30 & - \\
\hline Saccharomyces Cerevisiae (CFU/ewe/d) & - & - & - & - & - & $4 \times 109$ \\
\hline \multicolumn{7}{|l|}{ Chemical Composition } \\
\hline Total Digestible Nutrients (\%) & - & 78 & 78 & 78 & 78 & 78 \\
\hline ADF (\% DM) & & 26.7 & 26.7 & 26.7 & 26.7 & 26.7 \\
\hline NDF (\% DM) & & 38.6 & 38.6 & 38.6 & 38.6 & 38.6 \\
\hline Crude Protein (\%) & - & 13.2 & 13.2 & 13.2 & 13.2 & 13.2 \\
\hline Digestible Energy (Mcal/Kg) & - & 3.41 & 3.41 & 3.41 & 3.41 & 3.41 \\
\hline Metabolizable Energy (Mcal/Kg) & - & 3.01 & 3.01 & 3.01 & 3.01 & 3.01 \\
\hline
\end{tabular}

A) Control (only used Basal diet).

B) Flushing diet.

C) Flushing diet plus vitamin E plus Selenoprotein.

D) Flushing diet plus vitamin E plus Sodium Selenite.

E) Flushing diet plus Monensin.

F) Flushing diet plus Saccharomyces cerevisiae yeast.

\section{Blood sampling}

Blood samples were collected from the jugular vein at threetime intervals including: onset of experimental period (15days prior to mating), 24hours after removing CIDR (estrus phase) and 21days after mating (embryo implantation). After blood sampling, the blood samples were centrifuged for $12 \mathrm{~min}\left(1800 \times \mathrm{g}\right.$ at $\left.18^{\circ} \mathrm{C}\right)$ to separate the sera. After isolation all sera were frozen at $-20 \mathrm{oC}$ until further analysis. All materials and kits used for determination of blood elements were checked prior to experiment. Concentration of magnesium and calcium were determined by commercial kits 
(Pars Azmoon- Iran) using spectrophotometer set. Also, sodium and potassium concentrations were measured with flame photometery (Elico, Model Cl 360, India).

\section{Statistical Analyses}

Initially normality test was performed in order to remove overshoot data. Data were analyzed by SAS 2003 [10] software and mixed procedure and Tukey-Kramer test was used for means comparison. Used model was as follows:

In this model, $\mathrm{y}_{\mathrm{ijk}}$ : mean of one parameter, $\mu$ : mean of society, Treat: ${ }_{i}$ effect of treatment i, (Treat* Time) ${ }_{i j}$ : interaction between time and treatment, Animal ${ }_{1}$ effect of animal $l$ and $e_{i j \mathrm{jl}}$ : effect of error or residue.

\section{Results}

\section{Reproductive performancess}

Results from this study showed that the ratio of male to female lambs was higher in treatments D and C (Table 2). Ratio of male to female lambs was higher in sodium selenite plus vitamin $\mathrm{E}$ group compared with other treatments (2.5). Also, data in Table2 represents that treatment $\mathrm{F}$ with 12 female lambs and treatment E with 9 female lambs resulted in more female lambs compared with other treatments. Treatment $\mathrm{F}$ had the lowest ratio of male to female lambs (0.25).

Table 2: Gender of lamb births and ratio of male to female lambs.

\begin{tabular}{|c|c|c|c|}
\hline Treatments & Male & Female & Ratio of Male/Female \\
\hline A & 6 & 6 & 1 \\
\hline B & 5 & 6 & 0.83 \\
\hline C & 9 & 6 & 1.5 \\
\hline D & 10 & 4 & 2.5 \\
\hline E & 6 & 9 & 0.67 \\
\hline F & 3 & 12 & 0.25 \\
\hline
\end{tabular}

\section{Metabolites}

Table 3: The effect of different diets during the flushing period on serum Calcium concentration (mg/d; mean \pm SEM).

\begin{tabular}{|c|c|c|c|}
\hline Treatments & T1 & T2 & T3 \\
\hline A & $8.13 \pm 0.17$ & $8.18 \pm 0.05^{\mathrm{b}}$ & $8.02 \pm 0.13^{\mathrm{b}}$ \\
\hline B & $8.17 \pm 0.08$ & $8.51 \pm 0.16^{\mathrm{ab}}$ & $8.33 \pm 0.08^{\mathrm{b}}$ \\
\hline C & $8.16 \pm 0.11$ & $7.42 \pm 0.27^{\mathrm{c}}$ & $7.15 \pm 0.12^{\mathrm{c}}$ \\
\hline D & $8.04 \pm 0.21$ & $7.35 \pm 0.11^{\mathrm{c}}$ & $7.08 \pm 0.10^{\mathrm{c}}$ \\
\hline E & $8.22 \pm 0.14$ & $8.91 \pm 0.15^{\mathrm{a}}$ & $8.94 \pm 0.09^{\mathrm{a}}$ \\
\hline F & $8.09 \pm 0.12$ & $9.02 . \pm 0.10^{\mathrm{a}}$ & $9.18 \pm 0.17^{\mathrm{a}}$ \\
\hline
\end{tabular}

Means within same column with different superscripts differ $(P<0.01$

T1: 15 Days Prior to Mating.

T2: Estrus Phase.

T3: 21 Days after Mating.

This study results showed that calcium and magnesium levels in selenoprotein plus vitamin $\mathrm{E}$ and sodium seleniteplus vit $\neg$ amin
E treatments were significantly lower than other groups $(\mathrm{P}<0.01)$ during estrus and 21days after mating (Tables 3 \&4).Also, results of this study showed that calcium and magnesium levels were higher in Monensin sodium and Saccharomyces Cerevisiaeyeast treatments compared with other treatments significantly $(\mathrm{P}<0.01)$ and interestingly, the rate of female lamb births was higher in these two groups (Tables 3 and 4).

Table 4: The effect of different diets during the flushing period on serum Magnesium concentration (mg/d; mean \pm SEM)

\begin{tabular}{|c|c|c|c|}
\hline Treatments & T1 & T2 & T3 \\
\hline A & $2.39 \pm 0.04$ & $2.34 \pm 0.09^{\mathrm{b}}$ & $2.21 \pm 0.17^{\mathrm{b}}$ \\
\hline B & $2.24 \pm 0.07$ & $2.49 \pm 0.11^{\mathrm{b}}$ & $2.58 \pm 0.14^{\mathrm{ab}}$ \\
\hline C & $2.31 \pm 0.12$ & $1.94 \pm 0.07^{\mathrm{c}}$ & $1.63 \pm 0.18^{\mathrm{c}}$ \\
\hline D & $2.27 \pm 0.10$ & $1.82 \pm 0.14^{\mathrm{c}}$ & $1.74 \pm 0.09^{\mathrm{c}}$ \\
\hline E & $2.18 \pm 0.14$ & $2.81 \pm 0.06^{\mathrm{a}}$ & $3.05 \pm 0.14^{\mathrm{a}}$ \\
\hline F & $2.33 \pm 0.02$ & $2.90 \pm 0.10^{\mathrm{a}}$ & $3.01 \pm 0.05^{\mathrm{a}}$ \\
\hline
\end{tabular}

Means within same column with different superscripts differ $(P<0.01)$

T1: 15 Days Prior to Mating.

T2: Estrus Phase.

T3: 21 Days after Mating.

This study results showed that sodium concentration in selenoprotein plus vitamin E (treatment C) and sodium seleniteplus vitamin $\urcorner$ E (treatment D) were higher than flushing diet plus Monensin (treatment E) and Flushing diet plus Saccharomyces cerevisiaeyeast (treatment F) significantly $(\mathrm{P}<0.01)$ during estrus phase. Also, sodium concentration in ewes of groups $\mathrm{E}$ and $\mathrm{F}$ was higher than Control (only used Basal diet) and Flushing diet (treatment B) during estrus phase, but 21days after mating, only treatment $\mathrm{C}$ and $\mathrm{D}$ were significantly different with other treatments $(\mathrm{P}<0.01$; Table 5).Results also showed that serum potassium concentration in treatments $C$ and $D$ was significantly different with other treatments in estrus phase and 21days after mating $(\mathrm{P}<0.01)$, but not significantly different between other treatments (Table 6).

Table 5: The effect of different diets during the flushing period on serum Sodium concentration $(\mathrm{mEq} / \mathrm{l})$; mean \pm SEM).

\begin{tabular}{|c|c|c|c|}
\hline Treatments & T1 & T2 & T3 \\
\hline A & $132.6 \pm 1.18$ & $138.3 \pm 1.14^{\mathrm{b}}$ & $137.1 \pm 1.09^{\mathrm{b}}$ \\
\hline B & $132.4 \pm 1.21$ & $137.4 \pm 0.17^{\mathrm{b}}$ & $139.4 \pm 1.13^{\mathrm{b}}$ \\
\hline C & $131.8 \pm 1.38$ & $146.4 \pm 1.9^{\mathrm{a}}$ & $148.1 \pm 1.24^{\mathrm{a}}$ \\
\hline D & $132.3 \pm 1.12$ & $147.3 \pm 1.15^{\mathrm{a}}$ & $151.7 \pm 1.16^{\mathrm{a}}$ \\
\hline E & $132.1 \pm 1.23$ & $133.5 \pm 1.24^{\mathrm{c}}$ & $140.1 \pm 1.21^{\mathrm{b}}$ \\
\hline F & $132.5 \pm 1.25$ & $133.4 \pm 1.19^{\mathrm{c}}$ & $139.8 \pm 1.14^{\mathrm{b}}$ \\
\hline
\end{tabular}

Means within same column with different superscripts differ $(P<0.01)$

T1: 15 Days Prior to Mating.

T2: Estrus Phase.

T3: 21 Days after Mating. 
Table 6: The effect of different diets during the flushing period on serum Potassium concentration $(\mathrm{mEq} / \mathrm{l})$; mean \pm SEM)

\begin{tabular}{|c|c|c|c|}
\hline Treatments & T1 & T2 & T3 \\
\hline A & $4.53 \pm 0.07$ & $4.52 \pm 0.03^{\mathrm{b}}$ & $4.49 \pm 0.01^{\mathrm{b}}$ \\
\hline B & $4.52 \pm 0.09$ & $4.53 \pm 0.02^{\mathrm{b}}$ & $4.53 \pm 0.04^{\mathrm{ab}}$ \\
\hline C & $4.51 \pm 0.06$ & $4.78 \pm 0.03^{\mathrm{a}}$ & $4.66 \pm 0.02^{\mathrm{a}}$ \\
\hline D & $4.52 \pm 0.06$ & $4.79 \pm 0.06^{\mathrm{a}}$ & $4.62 \pm 0.04^{\mathrm{a}}$ \\
\hline E & $4.54 \pm 0.08$ & $4.55 \pm 0.05^{\mathrm{b}}$ & $4.48 \pm 0.05^{\mathrm{b}}$ \\
\hline F & $4.56 \pm 0.04$ & $4.54 \pm 0.04^{\mathrm{b}}$ & $4.45 \pm 0.06^{\mathrm{b}}$ \\
\hline
\end{tabular}

Means within same column with different superscripts differ $(P<0.01)$

T1: 15 Days Prior to Mating.

T2: Estrus Phase.

T3: 21 Days after Mating.

\section{Discussion}

Due to Selenoprotein function of selenium, it plays a major role in regulation of normal growth and development of several organs, especially reproductive organ of fetus $[8,11]$. Although using selenium and vitamin E may have different results, these results may be due to dose of selenium and vitamin E used before, during and after mating and selenium and vitamin E levels of ewe blood [10]. Results from this study showed that the ratio of male to female lambs was higher in treatments $\mathrm{D}$ and $\mathrm{C}$, which is consistent with E $\neg$ l-Shahat and Abdel Monem [13]results. The high levels of sodium in the Selenoprotein and sodium selenite may be effective on the level of serum sodium and potassium and, in result, effective on offspring sex ratio.

They suggestedthat different number of ions in rat's diet could have different effects on rat's offspring sexes [14]. To get male progeny, high serum levels of sodium and potassium and low levels of calcium and magnesium are required. In rats, a maternal diet high in sodium and potassium but low in calcium affects the sex ratio of offspring [15].This station cause changes in ovum metabolism and especially its outer layer so that spermatozoids carrying chromosome for male gender are attracted toward ovum. Moreover, in order for absorption of spermatozoid carrying female gender chromosome by ovum high levels of calcium and magnesium and low levels of potassium and sodium are necessary [4]. In an experiment on sows to check whether the mineral imbalance in the diet of the female before fertilization affects the sex ratio of the progeny, out of a total of 677 births, the sex ratio was 55.7 with the sodium and potassium diet and 48.3 with the calcium and magnesium diet [14]. Celik et al. [5] and BehnamRassouli et al.[6] reported that ration consisting of high levels of sodium and potassium caused the number of male sex to increase in each gestation, although this finding is inconsistent.

There was a significantly higher $\mathrm{Mg}$ concentration in ewes receiving Monensin, in fact, the Monensin effect on $\mathrm{Mg}$ is in agreement with Taghipoor et al. [7]who found both Mg absorption and retention increased when steers were fed Monensin. Greene et al. [17]found that the increase in magnesium absorption with Monensin feeding resulted from increased pre-intestinal absorption. Chandraju et al. [18] reported that in rats that consumed magnesium and calcium diet, out of a total of 98 offspring, 23 male (23.46\%) and 77 females (76.54\%) were born but in control group out of a total of 100 offspring, 50 female (50\%) and 50 male (50\%) progeny were born. O'Conner \& Beede [19] found that Monensin increased in vitro magnesium absorption by ovine duodenal tissue.

In addition to actually forming a complex with and altering transport of a given cation, ionophores may indirectly affect absorption of minerals through a coupled transport mechanism involving sodium and potassium or through changes in energy available for ion transport via altered monovalent ion gradients [20]. Increased magnesium absorption associated with ionophore feeding may result from increased $\mathrm{Na}^{*} / \mathrm{K}^{*}$-ATPase activity. Also, it has been documented that monensin could alter ions flow across intestinal epithelium cells and increase absorption of calcium, selenium and other cations [21].

Numerous research studies have shown that yeast significantly affects the acid-base balance in blood [22,23]. Milewskiet al. [24] reported thatcalcium and potassium concentrations in ewe's serum were higher when ewes consumed Saccharomyces Cerevisiaedry yeast in amount of $50 \mathrm{gram} / \mathrm{kg}$ concentrate compared with control group but these differences were not significant. While a decrease in magnesium concentrations in the blood serum of cows fed yeast was reported by Nikkhah et al. [25], in the described experiment, feed was supplemented with live yeast cultures. Although our results showed that Saccharomyces Cerevisiaeyeast increases blood calcium and magnesium, it does not have a significant effect on blood potassium levels compared to groups A and B.The underlying mechanism has not been fully explained, and it could be attributed to the ability of selected cations to bind across the yeast cell wall, which limits cation absorption from feed [23].

Maternal skewing of offspring sex ratio might have importantagricultural implications. Offspring of one gendermay be preferred over the other. For instance, females (ewe) arepreferred in the dairy industry and generation, whereas males (ram) are favoredin the meat industry. Altering the diet content prior to breedingmight provide a means of manipulating the sex ratio,e.g., a lower plane of nutrition might result in more femaleoffspring. Furthermore, foods with high levels of sodium, phosphor, iron, potassium and zinc (Selenoprotein and sodium selenite) increase $\mathrm{pH}$ of the uterus and sperm carrying male sex chromosome have high viability in alkaline stations. Using diet with high content of calcium, magnesium and copper such as dairy products, Monensin and yeasts decrease uterus $\mathrm{pH}$ and result in female offspring owing to high viability of female chromosome in acidic pH. Importantly, the diet of the mother, both before and after conception, needs to be considered as causative factors in skewing offspring sex ratio in animals. 


\section{Conclusion}

It has been suggested that in order to achievemale progeny high levels of sodium and potassium and low levels of calcium and magnesium resulted in changes of ovum metabolism and especially its outer layer so that spermatozoids carrying chromosome for male sex are attracted toward ovum, and in order for absorption of spermatozoid of female sex chromosome by ovum high levels of calcium and magnesium and low levels of potassium and sodium are necessary. Overall, results from this study showed that the serum potassium and sodium in ewes of groups $C$ and D were higher than other groups in estrus phase and on the 21st day of mating and the rate of male lamb births was higher than female lambs in these two groups. Results also showed that ewes in groups $\mathrm{E}$ and $\mathrm{F}$ had more calcium and magnesium compared with other groups and female lambs' births were the highest in these two groups. Totally, although the accuracy of these results is low, to increase the accuracy of experiments it may be suggested that other additives should be used in further studies and other elements such as iron, zinc and other enzymes involved in reproduction must be measured.

\section{References}

1. Pergament E, Todydemir PB, Fiddler M (2002) Sex ratio: a biological perspective of 'Sex and the City'. Reprod Biomed Online 5(1): 43-46.

2. Jongbloet PH (2004) Over-ripeness ovopathy: a challenging hypothesis for sex ratio modulation. Hum Reprod 19(4): 769-774.

3. Rosenfeld CS, Roberts RM (2004) Maternal diet and other factors affecting offspring sex ratio: a review. Biol Reprod 71(4): 1063-1070.

4. Grant VJ (2007) Could maternal testosterone levels govern mammalian sex ratio deviations?. J. Theoret Bio 246(4): 708-719.

5. Çelik K, Serbest S, Vurur S, Pala A, Daglioglu K (2003) Experiments to investigate the factors that affect the rate of sex constitution. Pak J Nutr 2: $238-241$

6. Behnam-Rassouli M, Aliakbarpour A, Hosseinzadeh H, BehnamRassouli F, Chamsaz M (2010) Investigating the effect of aqueous extract of Chicorium intybus L. leaves on offspring sex ratio in rat. Phytother Res 24(9): 1417-1421.

7. Taghipoor B, Seifi HA, Mohri M, Farzaneh N, Naserian AA (2011) Effect of prepartum administration of monensin on metabolism of pregnant ewes. Livestock Science 2(3): 231-237.

8. Rae MT, Kyle CE, Miller DW, Hammond AJ, Brooks AN, et al. (2002) The effects of undernutrition, in utero, on reproductive function in adult male and female sheep. Anim Reprod Sci 72(1-2): 63-71.

9. NRC (1985) Nutrient Requirements of Sheep, Sixth Revised Edition. National Academy Press, Washington DC, USA.
10. SAS Institute Inc., 2003. SAS Users Guide. SAS Institute Inc., Cary, NC, USA.

11. Kohrle J, Jakob F, Contempre B, Dumont JE (2005) Selenium, the thyroid, and the endocrine system. Endocr Rev 26(7): 944-984.

12. Rooke JA, Robinson JJ, Arthur JR (2004) Effects of vitamin E and selenium on the performance and immune status of ewes and lambs. J Agric Sci 142(3): 253-262.

13. El-Shahat KH, Abdel Monem UM (2011) Effects of dietary supplementation with vitamin $\mathrm{E}$ and/or selenium on metabolic and reproductive performance of Egyptian Baladi ewes under subtropical conditions. World Appli Sci J 12(9): 1492-1499.

14. Vahidi AR, Sheikhha MH (2001) Comparing the effects of sodium and potassium diet with calcium and magnesium diet on sex ratio of rats' offspring. Pak J Nutr 6(1): 44-48.

15. Bird E, Contreras RJ (1986) Maternal dietary sodium chloride levels affect the sex ratio in rat litters. Physiol Behav 36(2): 307-310.

16. Bolet G, Gueguen L, Dando P, Ollivier L (1982) Influence of mineral diet of the sow on the sex ratio of the newborn. Nutr Dev 22(6):1073-1081.

17. Greene LW, May BJ, Schelling GT, Byers FM (1988) Site and extent of apparent magnesium and calcium absorption in steers fed monensin. J Anim Sci 66(11): 2987-2991.

18. Chandraju S, Beirami A, Kumar C (2013) Impact of calcium and magnesium ions in identification of offspring gender in rats. Int $j$ pharm chem biol sci 3(1): 19-24.

19. O'Conner AM, Beede DK (1986) Effects of lasalocid and monensin on in vitro apparent absorption of magnesium and sodium by duodenal tissue in Ussing chambers. J Anim Sci 1: 447.

20. Lee DB, Brautbar N, Kleeman CR (1981) Disorders of phosphorus metabolism. New York, USA, Ny 3, pp. 283-421.

21. Beckett S, Lean I, Dyson R, Tranter W, Wade L (1998) Effects of monensin on the reproduction, health, and milk production of dairy cows. J Dairy Sci 81(6): 1563-1573.

22. Galıp N (2006) Effect of supplemental yeast culture and sodium bicarbonate on ruminal fermentation and blood variables in rams. J Anim Physiol Anim Nutr90(11-12): 445-452.

23. García CC, Mendoza MG, González MS, Cobos PM, Ortega CM, et al (2000) Effect of a yeast culture (Saccharomyces cerevisiae) and monensin on ruminal fermentation and digestion in sheep. Anim Feed Sci Technol 83(2): 165-170.

24. Milewski S, Sobiech P, Zabek K, Zarczynska K, Antoszkiewicz Z, et al. (2012) Effect of Saccharomyces cerevisiae yeast on milk protein content and composition and serum mineral concentrations in sheep. J Elem 20(1): 79-86.

25. Nikkhah A, Bonadaki MD, Zali A (2004) Effects of feeding yeast (Saccharomyces cerevisiae) on productive performance of lactating Holstein dairy cow. Iranian J Agric Sci 5: 53-59. 


\section{Your next submission with Juniper Publishers} will reach you the below assets

- Quality Editorial service

- Swift Peer Review

- Reprints availability

- E-prints Service

- Manuscript Podcast for convenient understanding

- Global attainment for your research

- Manuscript accessibility in different formats ( Pdf, E-pub, Full Text, Audio)

- Unceasing customer service

Track the below URL for one-step submission https://juniperpublishers.com/online-submission.php 